\title{
Respiratory mechanics measured by forced oscillation technique in rheumatoid arthritis-related pulmonary abnormalities: frequency-dependence, heterogeneity and effects of smoking
}

Risa Sokai ${ }^{1+}$, Satoru Ito ${ }^{1 * \dagger}$, Shingo Iwano ${ }^{2}$, Akemi Uchida ${ }^{3}$, Hiromichi Aso ${ }^{1}$, Masashi Kondo ${ }^{1}$, Naoki Ishiguro ${ }^{4}$, Toshihisa Kojima ${ }^{4}$ and Yoshinori Hasegawa ${ }^{1}$

\begin{abstract}
Rheumatoid arthritis (RA)-related pulmonary disorders specifically airway abnormalities and interstitial pneumonia (IP) are important extra-articular manifestations. The forced oscillation technique (FOT) is a useful method to assess respiratory impedance, respiratory resistance (Rrs) and reactance (Xrs), at different oscillatory frequencies during tidal breathing. The aim of this study was to characterize the respiratory mechanics of patients with RA and to relate them to parameters of the pulmonary function test and findings of chest $C T$ images. Respiratory impedance of RA patients ( $n=69$ ) was measured as a function of frequency from 4 to $36 \mathrm{~Hz}$ using the FOT device and compared with that of healthy subjects $(n=10)$. Data were retrospectively reviewed. Patients were female-dominant $(60.9 \%)$ and $95.7 \%$ had abnormal CT findings including airway and parenchymal abnormalities. Thirty-seven of 69 patients (53.6 \%) were smokers. Rrs was significantly frequency-dependent in RA patients but not in the healthy subjects. Xrs were significantly frequency-dependent in both RA and healthy groups. Rrs was significantly higher during an expiratory phase in both RA and healthy groups. Xrs was significantly lower (more negative) during an expiratory phase than that during an inspiratory phase in RA patients but not in healthy subjects. Xrs of the RA group was significantly more negative than that of the normal control. There was no difference in impedance parameters between the airway lesion dominant $(n=27)$ and IP dominant groups $(n=23)$ in the RA group. The impedance parameters of the RA group significantly correlated with most parameters of the pulmonary function test. In pulmonary function test results, $\%$ of the predicted value for forced expiratory flow from 25 to $75 \%$ of forced vital capacity was significantly lower and \% of the predicted value for diffusing capacity of the lung for carbon monoxide was higher in the airway lesion dominant group than those in the IP dominant group. Krebs von den Lungen-6, a serum indicator of IP, was significantly higher in the IP group than that in the airway lesion dominant group. Taken together, the impedance results reflect abnormalities in pulmonary functions and structures in patients with RA.
\end{abstract}

Keywords: Airway, Forced oscillation technique, Impedance, Interstitial lung disease, MostGraph, Rheumatoid arthritis

\footnotetext{
*Correspondence: itori@med.nagoya-u.ac.jp

${ }^{\dagger}$ Risa Sokai and Satoru Ito contributed equally to the present work

${ }^{1}$ Department of Respiratory Medicine, Nagoya University School

of Medicine, Nagoya 466-8550, Japan

Full list of author information is available at the end of the article
}

\section{Springer}

(C) 2016 Sokai et al. This article is distributed under the terms of the Creative Commons Attribution 4.0 International License (http://creativecommons.org/licenses/by/4.0/), which permits unrestricted use, distribution, and reproduction in any medium, provided you give appropriate credit to the original author(s) and the source, provide a link to the Creative Commons license, and indicate if changes were made. 


\section{Background}

Rheumatoid arthritis (RA) is a systemic inflammatory disease associated with extra-articular diseases including pulmonary diseases (Perez et al. 1998; Turesson et al. 2003; Brown 2007). RA-related pulmonary disorders, specifically interstitial pneumonia (IP) and airway abnormalities, are recognized as an important extra-articular manifestation because they are responsible for a significant portion of the mortality (Brown 2007; Olson et al. 2011; Tsuchiya et al. 2011). Computed tomography (CT) of the lung and pulmonary function tests have been used widely to manage the pulmonary abnormalities of patients with RA (Cortet et al. 1997; Fuld et al. 2003; Biederer et al. 2004; Tanaka et al. 2004; Mori et al. 2008, 2011).

The forced oscillation technique (FOT) is an accurate method to assess respiratory mechanics from input impedance measurements (Dubois et al. 1956; Grimby et al. 1968; Michaelson et al. 1975). This method is less dependent on patient effort than spirometry. Another benefit of FOT is that it enables measurement of both inspiratory and expiratory parameters during tidal breathing (Cauberghs and Van de Woestijne 1992; Peslin et al. 1992; Dellaca et al. 2004; Kanda et al. 2010; Paredi et al. 2010; Fujii et al. 2015). Measurement of respiratory system impedance (Zrs), respiratory resistance (Rrs) and reactance (Xrs), has been used successfully to assess respiratory functions of normal subjects and patients with respiratory diseases such as asthma, chronic obstructive pulmonary disease (COPD), and interstitial lung disease (van Noord et al. 1989; Dellaca et al. 2004; Kanda et al. 2010; Paredi et al. 2010; Ohishi et al. 2011; Ito et al. 2012; Miranda et al. 2013; Shirai et al. 2013; Sugiyama et al. 2013; Fujii et al. 2015; Hasegawa et al. 2015). Rrs reflects the extent of airflow obstruction (Di Mango et al. 2006; Hasegawa et al. 2015). Xrs is determined by the elastic properties of the respiratory system at the lowest frequency and the inertive properties at higher frequencies (Oostveen et al. 2003). It is expected that FOT will be able to identify respiratory abnormalities in patients with RA that are not detectable by spirometric examinations (Faria et al. 2012). However, the Zrs assessed by this technique has not been fully evaluated in patients with RA-related pulmonary diseases yet.

The purpose of the present study was to characterize the respiratory mechanics measured by FOT in patients with RA and to relate them to parameters of pulmonary function tests and findings of chest CT images. In addition, frequency-dependent and withinbreath behavior of the respiratory mechanics were also evaluated.

\section{Results}

Clinical characteristics and pulmonary function test results The characteristics and laboratory and pulmonary function test results of the 69 patients with RA shown in Table 1. 88.2\% were positive for anti-cyclic citrullinated peptide (anti-CCP) antibody ( $\geq 4.5 \mathrm{U} / \mathrm{ml}$ ), and $86.3 \%$ were positive for rheumatoid factor $(\mathrm{RF})(\geq 20.0 \mathrm{U} / \mathrm{ml})$. Next, the characteristics and pulmonary function test results of the airway lesion predominant and IP predominant groups were compared. The predominant CT patterns were classified as: airway lesion predominant $(\mathrm{n}=27,39.1 \%)$, IP predominant $(\mathrm{n}=23,33.3 \%)$, mixed pattern of airway abnormalities and IP $(\mathrm{n}=5$, $7.2 \%)$, other patterns $(\mathrm{n}=11,15.9 \%)$, or no abnormal findings ( $\mathrm{n}=3,4.3 \%$ ). Krebs von den Lungen-6 (KL6), a serum indicator of IP, was significantly higher in the IP group than those in the airway lesion dominant group (Table 1). Pulmonary function test results show that $\%$ of the predicted value for diffusing capacity of the lung for carbon monoxide $\left(\% \mathrm{DL}_{\mathrm{CO}}\right)$ and residual volume (RV)/total lung capacity (TLC) ratio were significantly higher and $\%$ of the predicted value for forced expiratory flow from 25 to $75 \%$ of forced vital capacity (FVC) $\left(\% \mathrm{FEF}_{25-75}\right)$, which reflects small airway diseases in RA (Mori et al. 2008; Mori et al. 2011), was lower in the airway lesion dominant group than that in the IP group (Table 1). Thirty-seven of 69 patients (53.6 \%) were smokers, but there were no significant difference in smoking history between the airway lesion dominant and IP groups (Table 1).

\section{CT findings}

Representative CT images of airway lesion dominant and IP dominant patterns are shown in Additional file 1: Figure S1. The characteristics, frequency, and grades of CT findings in all 69 cases, airway lesion predominant group $(\mathrm{n}=27)$, and IP predominant group $(\mathrm{n}=23)$ are shown in Table 2. Grades and frequency of CT findings of the airway lesion dominant and IP dominant groups were compared (Table 2). Characteristic CT findings of IP such as ground grass opacity, reticulation, honey combing, and traction bronchiectasis were more frequent in the IP dominant group. On the other hand, findings of bronchiectasis/bronchiolectasis and bronchiolar abnormality were more frequent in the airway lesion dominant group.

\section{Respiratory impedance of RA}

Rrs and Xrs results at a given frequency of all 69 patients are shown in Fig. 1. The Rrs values during a whole breath, inspiratory phase, and expiratory phase were significantly frequency-dependent $(P<0.001)$ and gradually decreased 
Table 1 Clinical characteristics and pulmonary function test results of investigated subjects

\begin{tabular}{|c|c|c|c|c|}
\hline Subjects & Total, $n=69$ & Airway, $n=27$ & $I P, n=23$ & $P$ value \\
\hline Age, years (range) & $65.5 \pm 10.1(39-86)$ & $65.6 \pm 9.4(39-80)$ & $62.5 \pm 9.6(39-78)$ & 0.253 \\
\hline Sex, male/female & $27 / 42$ & $8 / 19$ & $14 / 9$ & 0.053 \\
\hline Height, cm & $157.2 \pm 10.4$ & $155.2 \pm 8.5$ & $162.4 \pm 12.1$ & $0.016^{*}$ \\
\hline Weight, kg & $57.9 \pm 13.5$ & $55.2 \pm 12.9$ & $62.3 \pm 14.3$ & 0.071 \\
\hline BMI & $23.3 \pm 4.6$ & $22.9 \pm 5.3$ & $23.4 \pm 3.4$ & 0.729 \\
\hline Current/ex/never smokers & $9 / 28 / 32$ & 2/10/15 & $4 / 12 / 7$ & 0.177 \\
\hline Pack-years (range) & $45.8 \pm 34.8(0.8-147.0)$ & $41.0 \pm 34.2(0.8-105.0)$ & $47.3 \pm 34.7(1.2-147.0)$ & 0.639 \\
\hline Duration of RA, years & $12.5 \pm 10.1$ & $14.0 \pm 9.2$ & $8.5 \pm 6.3$ & $0.019^{*}$ \\
\hline Anti-CCP Ab, U/ml & $187.3 \pm 274.2(n=51)$ & $221.6 \pm 422.6(n=17)$ & $222.8 \pm 243.6(n=19)$ & 0.936 \\
\hline $\mathrm{RF}, \mathrm{IU} / \mathrm{ml}$ & $254.3 \pm 514.7(n=51)$ & $218.8 \pm 445.3(n=19)$ & $208.3 \pm 249.6(n=16)$ & 0.892 \\
\hline $\mathrm{KL}-6, \mathrm{U} / \mathrm{ml}$ & $492.7 \pm 336.2(n=58)$ & $394.3 \pm 270.9(n=22)$ & $646.0 \pm 388.7(n=21)$ & $0.018^{*}$ \\
\hline SP-D, ng/ml & $68.6 \pm 31.0(n=19)$ & $47.2 \pm 22.3(n=5)$ & $75.8 \pm 29.5(n=10)$ & 0.081 \\
\hline $\mathrm{LDH}, \mathrm{IU} / \mathrm{ml}$ & $214.5 \pm 44.7$ & $218.1 \pm 46.0$ & $213.7 \pm 52.1$ & 0.750 \\
\hline$\% \mathrm{VC}$ & $97.6 \pm 15.4$ & $95.6 \pm 16.6$ & $95.0 \pm 13.9$ & 0.938 \\
\hline$\% F V C$ & $99.9 \pm 17.7$ & $97.2 \pm 19.6$ & $97.9 \pm 16.2$ & 0.884 \\
\hline$\% \mathrm{FEV}_{1}$ & $87.8 \pm 19.1$ & $81.8 \pm 20.0$ & $89.3 \pm 19.3$ & 0.182 \\
\hline $\mathrm{FEV}_{1} / \mathrm{FVC}, \%$ & $71.1 \pm 10.3$ & $67.9 \pm 11.4$ & $74.5 \pm 7.8$ & $0.025^{*}$ \\
\hline $\mathrm{FEF}_{25-75} / \mathrm{FVC}, \%$ & $51.9 \pm 25.8$ & $44.0 \pm 25.1$ & $62.1 \pm 25.2$ & $0.016^{*}$ \\
\hline$\% \mathrm{FEF}_{25-75}$ & $52.6 \pm 25.7$ & $42.3 \pm 23.1$ & $63.1 \pm 24.8$ & $0.004^{*}$ \\
\hline$\% T L C$ & $102.2 \pm 15.3$ & $102.9 \pm 14.4$ & $97.7 \pm 16.2$ & 0.233 \\
\hline$\% R V$ & $100.1 \pm 22.1$ & $104.7 \pm 22.0$ & $92.5 \pm 21.3$ & 0.054 \\
\hline RV/TLC \% & $37.6 \pm 7.2$ & $39.6 \pm 7.9$ & $34.1 \pm 5.0$ & $0.006^{*}$ \\
\hline$\% L_{C O}$ & $97.0 \pm 22.0$ & $104.9 \pm 15.9$ & $80.1 \pm 20.0$ & $<0.001^{*}$ \\
\hline$\% D L_{C O} N_{A}$ & $99.7 \pm 26.3$ & $107.3 \pm 18.2$ & $84.1 \pm 25.8$ & $<0.001^{*}$ \\
\hline
\end{tabular}

Values are mean \pm SD. Values were compared using t-test, Chi square test, or Fisher's exact test

Anti-CCP Ab anti-cyclic citrullinated peptide antibody, $R F$ rheumatoid factor, $K L-6$ Krebs von den Lungen, a serum indicator of interstitial pneumonia, $S P$ - $D$ surfactant protein-D, FEV forced expiratory volume in $1 \mathrm{~s}, F V C$ forced vital capacity, VC vital capacity, $F E F_{25-75}$ forced expiratory flow from 25 to $75 \%$ of $F V C, T L C$ total lung capacity, $R V$ residual volume, $D L_{C O}$ diffusing capacity of the lung for carbon monoxide, $V_{A}$ alveolar volume

* Significantly different $(P<0.05)$ between the airway lesion dominant and IP dominant groups

as a function of frequency from 4 to $32 \mathrm{~Hz}$ but increased at $36 \mathrm{~Hz}$ (Fig. 1a). Rrs values were significantly higher during the expiratory phase than during the inspiratory phase $(P<0.001)$ at all frequencies (Fig. 1a). Xrs values during a whole breath, inspiration, and expiration were also significantly increased as a function of frequency (Fig. 1b). Expiratory Xrs values were significantly lower than inspiratory $\operatorname{Xrs}(P=0.004)$ specifically at lower frequencies $(4-20 \mathrm{~Hz})$ (Fig. 1b).

High prevalence (53.6\%) of smoking history in our RA cohort (Table 1) is an important cofounding factor. Thus, we compared the Zrs results of smokers $(n=37)$ with those of never smokers $(n=32)$. However, there was no difference in Rrs or Xrs during a whole breath between ever and never smokers (Additional file 2: Figure S2A and S2B). Moreover, differences between inspiratory and expiratory phases $(\Delta)$ in Xrs $(\Delta \mathrm{Xrs})$ calculated as mean inspiratory values minus mean expiratory values were not statistically significantly different between the groups (Additional file 2: Figure S2C).

\section{Respiratory impedance of healthy control subjects}

Next, we re-analyzed the Zrs results at a given frequency of the healthy control group of our previous study (age: 24-59 years, $\mathrm{n}=10$ ) (Uchida et al. 2013). The biometric and spirometric characteristics of the healthy control group are shown in Additional file 3: Table S1. Rrs was not significantly frequency-dependent during a whole breath, inspiratory phase, or expiratory phase (Fig. 2a) different from that in the RA group (Fig. 1a). Rrs values were significantly higher during the expiratory phase than during the inspiratory phase $(P<0.001)$ at most frequencies (Fig. 2a). Xrs values during a whole breath, inspiration, and expiration were also significantly increased as a function of frequency (Fig. 2b). There was no difference in Xrs between inspiratory and expiratory phases (Fig. 2b).

\section{Comparison of impedance between RA and control groups} Next, we compared the Zrs results of the RA and healthy control groups. Rrs was significantly 
Table 2 CT findings

\begin{tabular}{|c|c|c|c|c|}
\hline Findings, $\mathrm{n}(\%)$ & Total, $\mathrm{n}=69$ & Airway, $n=27$ & IP, $n=23$ & $P$ value \\
\hline Airspace consolidation & $25(36.2 \%)$ & $15(55.6 \%)$ & $5(21.7 \%)$ & \\
\hline Grade, median (range) & $0(0-2)$ & $1(0-1)$ & $0(0-1)$ & $0.034^{*}$ \\
\hline Ground grass opacity & $31(44.9 \%)$ & $5(18.5 \%)$ & $18(78.3 \%)$ & \\
\hline Grade, median (range) & $0(0-4)$ & $0(0-2)$ & $1(0-4)$ & $<0.001^{*}$ \\
\hline Reticulation & $41(59.4 \%)$ & $11(40.7 \%)$ & $20(87.0 \%)$ & \\
\hline Grade, median (range) & $1(0-3)$ & $0(0-1)$ & $1(0-3)$ & $<0.001^{*}$ \\
\hline Bronchovascular bundle thickening & $1(1.4 \%)$ & $1(3.7 \%)$ & 0 & \\
\hline Grade, median (range) & $0(0-1)$ & $0(0-1)$ & $0(0-0)$ & 0.377 \\
\hline Honeycombing & $10(14.5 \%)$ & 0 & $9(39.1 \%)$ & \\
\hline Grade, median (range) & $0(0-3)$ & $0(0-0)$ & $0(0-3)$ & $<0.001^{*}$ \\
\hline Nodules & $49(71.4 \%)$ & $26(96.3 \%)$ & $10(43.5 \%)$ & \\
\hline Grade, median (range) & $1(0-4)$ & $1(0-4)$ & $0(0-1)$ & $<0.001^{*}$ \\
\hline Emphysema & $20(29.0 \%)$ & $2(7.4 \%)$ & $13(56.5 \%)$ & \\
\hline Grade, median (range) & $0(0-3)$ & $0(0-2)$ & $1(0-3)$ & $<0.001^{*}$ \\
\hline Bullae & $24(34.8 \%)$ & $4(14.8 \%)$ & $13(56.5 \%)$ & \\
\hline Grade, median (range) & $0(0-1)$ & $0(0-1)$ & $1(0-1)$ & $<0.001^{*}$ \\
\hline Bronchiectasis or bronchiolectasis & $23(33.3 \%)$ & $19(70.4 \%)$ & 0 & \\
\hline Grade, median (range) & $0(0-2)$ & $1(0-2)$ & $0(0-0)$ & $<0.001^{*}$ \\
\hline Traction bronchiectasis & $20(29.0 \%)$ & $3(11.1 \%)$ & $17(73.9 \%)$ & $<0.001^{*}$ \\
\hline Crazy-paving appearance & $2(2.9 \%)$ & 0 & $2(8.7 \%)$ & 0.207 \\
\hline Tree-in-bud sign & $6(8.7 \%)$ & $5(18.5 \%)$ & 0 & 0.054 \\
\hline Architectural distortion & $14(20.3 \%)$ & $4(14.8 \%)$ & $8(34.8 \%)$ & 0.183 \\
\hline Pulmonary artery enlargement & $2(2.9 \%)$ & 0 & $1(4.3 \%)$ & 0.460 \\
\hline Esophageal dilatation & $15(21.7 \%)$ & $4(14.8 \%)$ & $8(34.8 \%)$ & 0.183 \\
\hline Lymph node enlargement & $16(23.2 \%)$ & $6(22.2 \%)$ & $5(21.7 \%)$ & 1 \\
\hline Pleural or pericardial effusion or thickening & $16(23.2 \%)$ & $6(22.2 \%)$ & $5(21.7 \%)$ & 1 \\
\hline Bronchiolar abnormality & $33(47.8 \%)$ & $25(92.6 \%)$ & $3(13.0 \%)$ & $<0.001^{*}$ \\
\hline
\end{tabular}

Airway airway lesion dominant pattern, IP interstitial pneumonia dominant pattern

* Significantly different $(P<0.05)$ between airway lesion and IP dominant groups (Mann-Whitney test or Fisher's exact test)

frequency-dependent in the RA group (Fig. 1a) but not in the healthy control group (Fig. 2a). As a results, there was a significant interaction in the Rrs curves $(P<0.001)$ between group (either the RA or healthy control) and frequency by two-way repeated-measure analysis of variance (ANOVA) during a whole breath (Fig. 3a), inspiration, and expiration. There was no significant difference between the groups in the mean values of Rrs during a whole breath (Fig. 3a), inspiration, and expiration. Xrs during a whole breath of the RA group was significantly lower (more negative) $(P=0.018)$ than that of the control group (Fig. 3b). Similarly, Xrs during inspiratory and expiratory phases was significantly more negative than that of the control group. $\Delta \mathrm{Xrs}$ was not statistically significantly different between the groups (Fig. 3c).

\section{Comparison of impedance between airway lesion and IP} dominant groups in RA

Next, we compared the Zrs results of the airway lesion dominant and IP dominant groups in RA patients. During a whole breath, inspiratory phase, and expiratory phase, Rrs and Xrs were significantly frequency-dependent $(P<0.001)$ in both groups. However, there was no significant difference between the groups in values of Rrs or Xrs (Fig. 4a, b). $\Delta$ Xrs was not statistically significantly different either (Fig. 4c).

\section{Correlations between impedance and pulmonary function test results}

Correlations between parameters of the Zrs and pulmonary function test are shown in Table 3. Rrs values at the lowest (4 Hz, R4), middle $(20 \mathrm{~Hz}, \mathrm{R} 20)$, and highest 

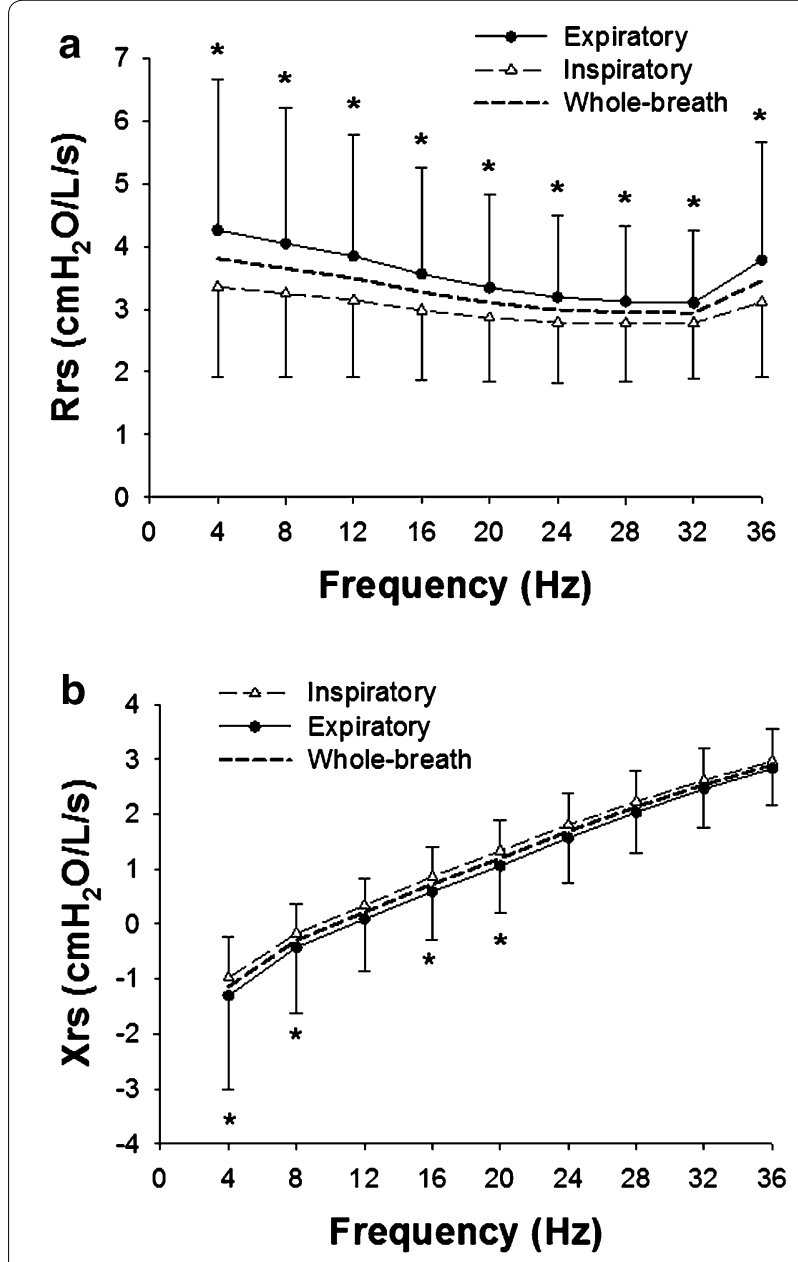

Fig. 1 Frequency dependences of respiratory impedance, respiratory resistance (Rrs) and reactance (Xrs) at 4-36 Hz, during a whole breath, inspiratory phase and expiratory phase, were examined. The Rrs (a) and Xrs (b) of all rheumatoid arthritis (RA) cases $(n=69)$ are shown. Values during inspiratory and expiratory phases are mean \pm SD $\left(\mathrm{cmH}_{2} \mathrm{O} / \mathrm{L} / \mathrm{s}\right)$. Averages of Rrs and Xrs during a whole breath are also shown (dashed lines). *Significant difference $(P<0.05)$ between inspiratory and expiratory phases by two-way repeated measure ANOVA, followed by Bonferroni test for post hoc analysis

(36 Hz, R36) frequencies during a whole breath were selected for analysis. $\Delta \mathrm{Xrs}$ at low frequencies is increased by expiratory flow limitation in patients with COPD (Dellaca et al. 2004) and becomes negative in restrictive disorder in patients with interstitial lung diseases (Sugiyama et al. 2013; Fujii et al. 2015). Therefore, Xrs and $\Delta$ Xrs at the lowest frequency ( $4 \mathrm{~Hz}, \mathrm{X} 4$ and $\Delta \mathrm{X} 4$, respectively) were selected for analysis. $\Delta \mathrm{X} 4$ significantly negatively correlated with $\% \mathrm{FVC}, \%$ of the predicted value for forced expiratory volume in $1 \mathrm{~s}\left(\% \mathrm{FEV}_{1}\right)$, and of the predicted value for TLC (\%TLC). Relationships between \%FVC and $\triangle \mathrm{X} 4$ for all cases and the IP dominant group are shown
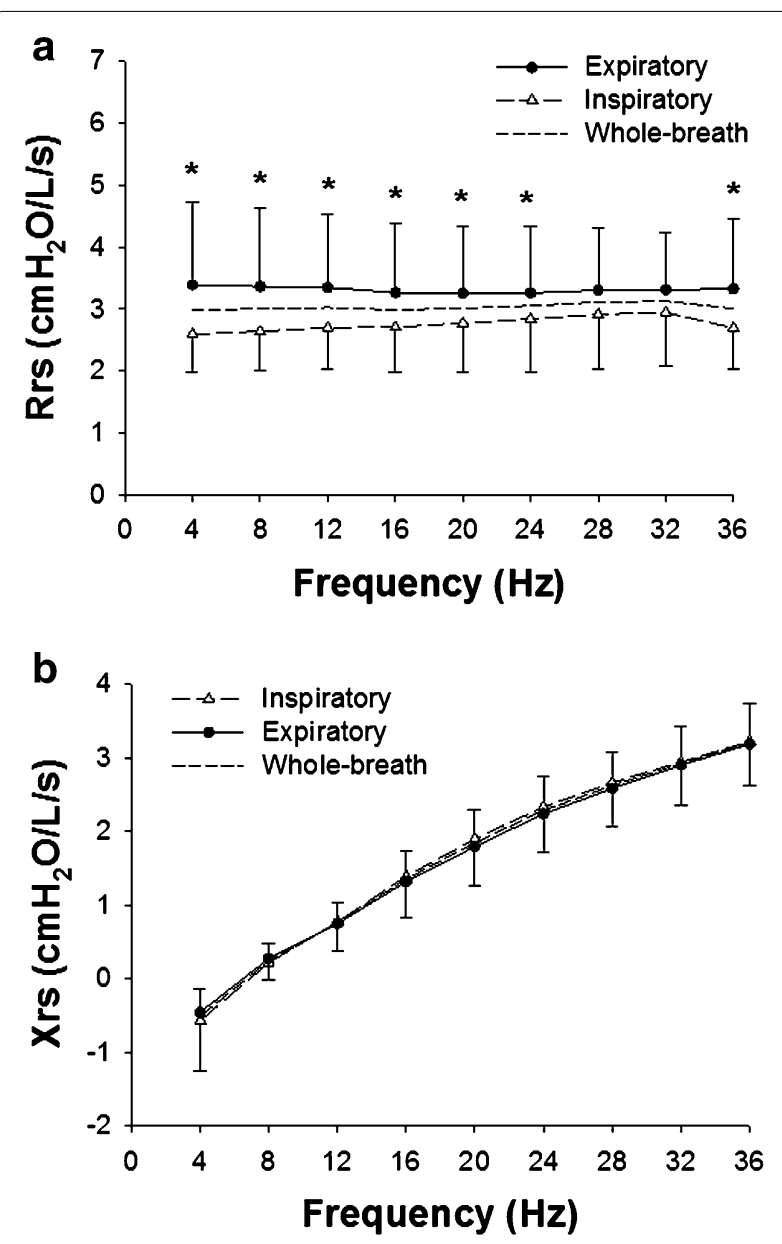

Fig. 2 Frequency dependences of the Rrs (a) and $\operatorname{Xrs}(\mathbf{b})$ of the healthy subjects $(n=10)$ are shown. Values during inspiratory and expiratory phases are mean $\pm \mathrm{SD}\left(\mathrm{cmH}_{2} \mathrm{O} / \mathrm{L} / \mathrm{s}\right)$. Averages of Rrs and Xrs during a whole breath are also shown (dashed lines). *Significant difference $(P<0.05)$ between inspiratory and expiratory phases by two-way repeated measure ANOVA, followed by Bonferroni test for post hoc analysis

(Fig. 5a, b). $\triangle \mathrm{X} 4$ also inversely correlated with $\% \mathrm{FVC}$ in the IP group alone $(r=-0.426, P<0.05$, Fig. $5 b)$.

\section{Association between $\mathrm{CT}$ findings and impedance results}

Next, we examined whether values of the Zrs parameters were affected by the existence of RA-related pulmonary abnormalities based on CT findings. Due to rare prevalence (prevalence $\leq 2$ in Table 2), bronchovascular bundle thickening $(\mathrm{n}=1)$, crazy-paving appearance $(n=2)$, and pulmonary artery enlargement $(n=2)$ in CT findings were excluded for the analysis. X4 during a whole breath was significantly lower (more negative) in patients with esophageal dilatation than those without $\left(-1.66 \pm 1.11 \mathrm{cmH}_{2} \mathrm{O} / \mathrm{L} / \mathrm{s}\right.$ vs. $-1.00 \pm 1.13 \mathrm{cmH}_{2} \mathrm{O} / \mathrm{L} / \mathrm{s}$, 

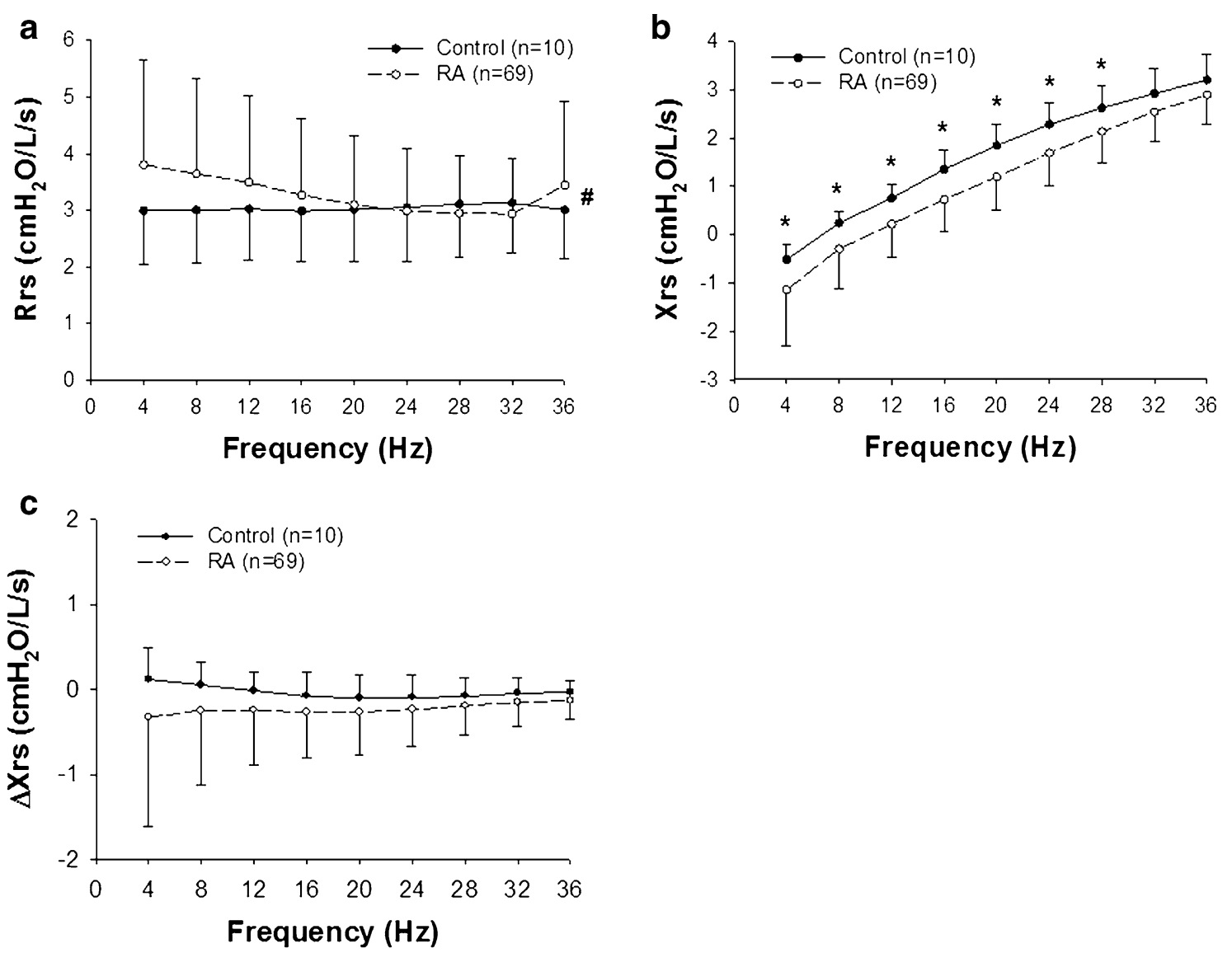

Fig. 3 Rrs (a) and Xrs (b) during a whole breath in the RA $(n=69)$ and healthy control groups $(n=10)$ are compared. $\mathbf{c}$ Differences between inspiratory and expiratory phases $(\Delta)$ in Xrs $(\Delta \mathrm{Xrs})$ calculated as mean inspiratory values minus mean expiratory values are also compared. Values are mean $\pm \mathrm{SD}\left(\mathrm{cmH}_{2} \mathrm{O} / \mathrm{L} / \mathrm{s}\right)$. ${ }^{*}$ Significant difference $(P<0.05)$ between inspiratory and expiratory phases by two-way repeated measure ANOVA, followed by Bonferroni test for post hoc analysis. "There was a significant interaction in the Rrs curves between the group (either the RA or healthy control) and frequency $(P<0.001)$

$P<0.05) . \Delta \mathrm{X} 4$ was significantly higher in patients with architectural distortion than those without $(1.05 \pm 2.27$ $\mathrm{cmH}_{2} \mathrm{O} / \mathrm{L} / \mathrm{s}$ vs. $\left.0.14 \pm 0.83 \mathrm{cmH}_{2} \mathrm{O} / \mathrm{L} / \mathrm{s}, P<0.05\right)$. Values of the Rrs parameters were not significantly affected by the existence of either CT finding.

\section{Discussion}

The main findings of the present study were that in patients with RA: (1) Rrs and Xrs values were significantly dependent on frequency and differed between expiratory and inspiratory phases, (2) Xrs values and frequency-dependent behavior in Rrs were significantly different from those of the healthy subjects, (3) impedance parameters significantly correlated with most parameters of the pulmonary function test, (4) impedance results were not significantly different between the airway lesion dominant and IP dominant groups, and (5) KL-6, $\% \mathrm{DL}_{\mathrm{CO}}, \mathrm{RV} / \mathrm{TLC}, \% \mathrm{FEF}_{25-75}$, and $\mathrm{FEV}_{1} / \mathrm{FVC}$ were significantly different between the airway lesion dominant and IP dominant groups. It has been reported that KL-6 is a useful serum marker reflecting IP specifically pulmonary fibrosis including in RA-related IP (Kinoshita et al. 2004). Parameters of the pulmonary function test such as $\% \mathrm{DL}_{\mathrm{CO}}, \mathrm{FEV}_{1} / \mathrm{FVC}$, and $\% \mathrm{FEF}_{25-75}$ have been used to evaluate functional impairment in pulmonary manifestations associated with RA (Fuld et al. 2003; Mori et al. 2008, 2011). Our findings are consistent with results of those previous reports. In contrast, Rrs, Xrs, or $\Delta \mathrm{Xrs}$ was not significantly different between the airway lesion dominant and IP dominant groups unexpectedly probably due to heterogeneity and large variability as one of characteristics of RA-related pulmonary abnormalities. To our knowledge, however, this is the first study to characterize the respiratory impedance measured by FOT and relate it to pulmonary functions and CT findings in patients with RA-related pulmonary diseases.

One of the advantages of FOT is the ability to evaluate Zrs over a range of frequencies (Dubois et al. 1956; 

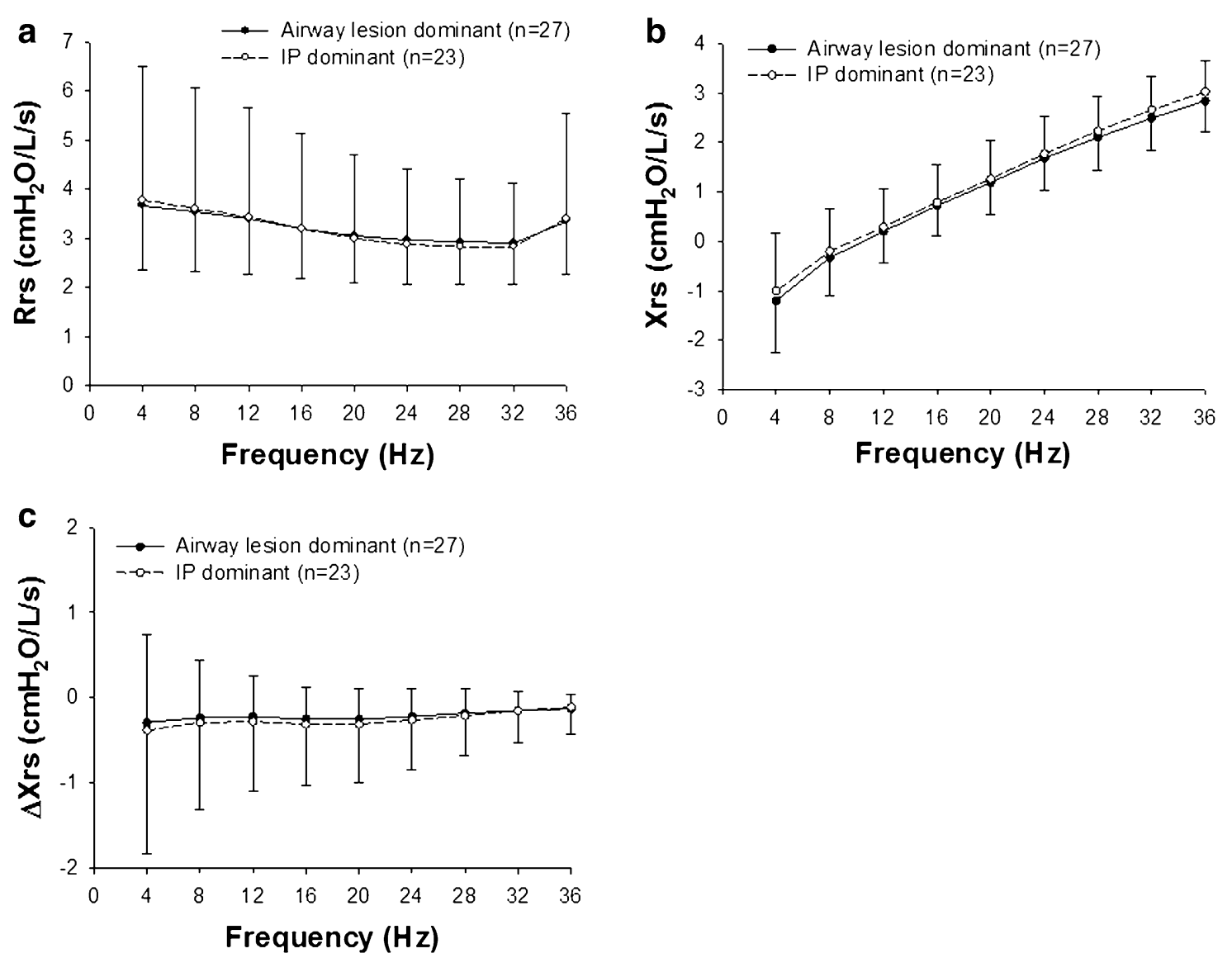

Fig. 4 Rrs (a) and Xrs (b) during a whole breath in the airway lesion dominant $(n=27)$ and interstitial pneumonia (IP) dominant groups $(n=23)$ are shown. $\mathbf{c} \Delta$ Xrs values are also compared in the airway lesion dominant $(\mathrm{n}=27)$ and IP dominant groups. Values are $\mathrm{mean} \pm \mathrm{SD}\left(\mathrm{cmH} \mathrm{H}_{2} \mathrm{O} / \mathrm{L} / \mathrm{s}\right)$ and compared by two-way repeated measure ANOVA, followed by Bonferroni test for post hoc analysis

Grimby et al. 1968; Michaelson et al. 1975; Hantos et al. 1992; Ito et al. 2007; Bates et al. 2011; Tanimura et al. 2014). We examined the Rrs and Xrs data at a given frequency between 4 and $36 \mathrm{~Hz}$ and found that the Rrs and Xrs of the RA group were significantly frequencydependent in all cases (Fig. 1) and airway lesion dominant and IP dominant groups (Fig. 4). It is generally known that Xrs increases from negative values to positive values in a frequency-dependent manner both in healthy subjects and patients with respiratory diseases (Oostveen et al. 2003; Bates et al. 2011) as found in the present study. In contrast, Rrs in healthy subjects was not significantly frequency dependent (Fig. 2). As a result, there was a significant interaction between the frequency and group when the Rrs values of RA and normal subjects were compared (Fig. 3a). The frequency-dependence of Rrs reflects the inhomogeneity in gas flow in the respiratory system specifically during bronchoconstriction as well as in patients with COPD and restrictive abnormality due to interstitial lung disease (van Noord et al. 1989;
Pride 1992; Lutchen et al. 1996). Taken together, the results suggest that the frequency-dependence in Rrs in medium frequency range derives from both airway and parenchymal abnormalities in patients with RA.

The within-breath behavior of the Zrs results showed that Rrs was significantly higher during the expiratory phase than that during the inspiratory phase in RA (Fig. 1a). Expiratory Xrs was slightly but significantly lower than inspiratory Xrs at lower frequencies in the RA group (Fig. 1b). However, there was no difference in $\Delta \mathrm{Xrs}$ between the airway lesion dominant and IP dominant groups (Fig. 4c). Dellaca et al. reported that $\Delta \mathrm{Xrs}$ at low frequencies is beneficial for detecting expiratory flow limitation in patients with COPD (Dellaca et al. 2004). They analyzed individual respiratory cycles and proposed $2.8 \mathrm{cmH}_{2} \mathrm{O} / \mathrm{L} / \mathrm{s}$ of $\Delta \mathrm{X} 5$ as an optimal threshold value of for expiratory flow limitation (Dellaca et al. 2004). In contrast to their analysis, we calculated the average of respiratory cycles during the Zrs measurements for $\Delta \mathrm{Xrs}$ analysis as reported by other groups (Kanda et al. 2010; 
Table 3 Correlation between parameters of impedance and pulmonary function tests

\begin{tabular}{|c|c|c|c|c|c|}
\hline & R4 & R20 & R36 & $\mathrm{X} 4$ & $\Delta \mathrm{X} 4$ \\
\hline \multicolumn{6}{|c|}{ Height } \\
\hline$R$ & -0.323 & -0.454 & -0.404 & 0.220 & 0.127 \\
\hline$P$ & $0.007^{*}$ & $<0.001^{*}$ & $<0.001^{*}$ & 0.070 & 0.300 \\
\hline \multicolumn{6}{|l|}{ VC } \\
\hline $\mathrm{R}$ & -0.380 & -0.429 & -0.412 & 0.480 & 0.017 \\
\hline P & $0.001^{*}$ & $<0.001^{*}$ & $<0.001^{*}$ & $<0.001^{*}$ & 0.892 \\
\hline \multicolumn{6}{|c|}{$\% \mathrm{VC}$} \\
\hline $\mathrm{R}$ & -0.140 & 0.022 & -0.044 & 0.497 & -0.229 \\
\hline P & 0.251 & 0.859 & 0.717 & $<0.001^{*}$ & 0.059 \\
\hline \multicolumn{6}{|c|}{ FVC } \\
\hline R & -0.424 & -0.456 & -0.445 & 0.519 & -0.032 \\
\hline P & $<0.001^{*}$ & $<0.001^{*}$ & $<0.001^{*}$ & $<0.0001^{*}$ & 0.7947 \\
\hline \multicolumn{6}{|c|}{ \%FVC } \\
\hline$R$ & -0.201 & -0.018 & -0.091 & 0.517 & -0.312 \\
\hline P & 0.098 & 0.884 & 0.457 & $<0.001^{*}$ & $0.009^{*}$ \\
\hline \multicolumn{6}{|c|}{$\mathrm{FEV}_{1}$} \\
\hline R & -0.428 & -0.395 & -0.418 & 0.506 & -0.024 \\
\hline P & $<0.001^{*}$ & $<0.001^{*}$ & $<0.001^{*}$ & $<0.001^{*}$ & 0.847 \\
\hline \multicolumn{6}{|c|}{$\% \mathrm{FEV}_{1}$} \\
\hline R & -0.220 & -0.018 & 0.109 & 0.485 & -0.240 \\
\hline$P$ & 0.069 & 0.883 & 0.375 & $<0.001^{*}$ & $0.047^{*}$ \\
\hline \multicolumn{6}{|c|}{$\mathrm{FEV}_{1} / \mathrm{FVC}$} \\
\hline R & -0.136 & -0.051 & -0.103 & 0.080 & 0.038 \\
\hline$P$ & 0.264 & 0.681 & 0.402 & 0.515 & 0.758 \\
\hline \multicolumn{6}{|c|}{$\mathrm{FEF}_{25-75}$} \\
\hline $\mathrm{R}$ & -0.299 & -0.235 & -0.275 & 0.314 & -0.002 \\
\hline P & $0.013^{*}$ & 0.052 & $0.022^{*}$ & $0.009^{*}$ & 0.985 \\
\hline \multicolumn{6}{|c|}{$\% F F_{25-75}$} \\
\hline R & -0.176 & -0.069 & -0.124 & 0.240 & -0.006 \\
\hline P & 0.147 & 0.573 & 0.310 & $0.047^{*}$ & 0.964 \\
\hline \multicolumn{6}{|c|}{$\mathrm{FEF}_{25-75} / \mathrm{FVC}$} \\
\hline R & -0.127 & -0.042 & -0.092 & 0.077 & 0.039 \\
\hline$P$ & 0.298 & 0.730 & 0.454 & 0.528 & 0.752 \\
\hline \multicolumn{6}{|c|}{ TLC } \\
\hline R & -0.380 & -0.442 & -0.421 & 0.454 & 0.028 \\
\hline$P$ & $0.0013^{*}$ & $0.0001^{*}$ & $0.0003^{*}$ & $<0.001^{*}$ & 0.817 \\
\hline \multicolumn{6}{|c|}{$\% T L C$} \\
\hline $\mathrm{R}$ & -0.148 & 0.051 & -0.033 & 0.501 & -0.301 \\
\hline P & 0.225 & 0.675 & 0.787 & $<0.001^{*}$ & $0.012^{*}$ \\
\hline \multicolumn{6}{|l|}{ RV } \\
\hline R & -0.162 & -0.227 & -0.205 & 0.099 & 0.086 \\
\hline P & 0.183 & 0.061 & 0.091 & 0.416 & 0.481 \\
\hline \multicolumn{6}{|c|}{ \%RV } \\
\hline R & -0.108 & -0.012 & -0.057 & 0.170 & -0.159 \\
\hline$P$ & 0.379 & 0.920 & 0.640 & 0.162 & 0.192 \\
\hline \multicolumn{6}{|c|}{ RV/TLC } \\
\hline R & 0.196 & 0.195 & 0.194 & -0.370 & 0.079 \\
\hline P & 0.107 & 0.109 & 0.111 & $0.002^{*}$ & 0.518 \\
\hline
\end{tabular}

Table 3 continued

\begin{tabular}{llllll}
\hline & R4 & R20 & R36 & \multicolumn{1}{l}{ X4 } & \multicolumn{1}{c}{$\mathbf{~ X 4}$} \\
\hline$\% D L_{C O}$ & & & & & \\
$\mathrm{R}$ & 0.064 & 0.088 & 0.077 & -0.002 & 0.011 \\
$P$ & 0.605 & 0.471 & 0.532 & 0.986 & 0.929 \\
\hline
\end{tabular}

Correlation coefficient $(\mathrm{R})$ and significance $(P)$ between parameters of impedance and height or pulmonary function test results. R4, R20, and $\mathrm{R} 36$, respiratory resistance (Rrs) at 4,20 , and $36 \mathrm{~Hz}$ during a whole breath, respectively; $\mathrm{X} 4$, respiratory reactance $(\mathrm{Xrs})$ at $4 \mathrm{~Hz}$ during a whole breath; $\Delta \mathrm{X} 4$ difference between mean inspiratory and mean expiratory phases $(\Delta)$ in $\operatorname{Xrs}$ $(\Delta \mathrm{Xrs})$ at $4 \mathrm{~Hz}$

* Statistically significant relationship $(P<0.05)$

Paredi et al. 2010; Mori et al. 2013; Sugiyama et al. 2013). In the present study, $\Delta \mathrm{X} 4$ values were above $2.8 \mathrm{cmH}_{2} \mathrm{O} /$ $\mathrm{L} / \mathrm{s}$ in four RA cases including two cases in the IP dominant group (Fig. 5) but not in the healthy subjects. Kanda et al. demonstrated that expiratory R5 was significantly higher than inspiratory R5, but there was no significant difference in $\Delta \mathrm{Xrs}$ at $5 \mathrm{~Hz}(\Delta \mathrm{X} 5)$ between the expiratory and inspiratory phases in the healthy subjects (Kanda et al. 2010). Similarly, we also found that Rrs was higher during the expiratory phase, but there was no significant difference in Xrs between the expiratory and inspiratory phases in the healthy subjects (Fig. 2). Interestingly, previous studies have demonstrated that inspiratory X5 of IP was significantly lower than expiratory X5 different from the findings in COPD (Mori et al. 2013; Sugiyama et al. 2013). In the present study, $\Delta X 4$ values of the airway lesion dominant and IP dominant groups were not different (Fig. 4c), inconsistent with findings in those previous reports (Mori et al. 2013; Sugiyama et al. 2013). There was a weak but significant negative correlation between $\triangle \mathrm{X} 4$ and $\% \mathrm{FVC}$ or \%TLC, an indicator of IP severity (Table 3; Fig. 5). Moreover, $\Delta \mathrm{X} 4$ with architectural distortion in the CT findings was significantly higher than that without. Although the origin of $\Delta \mathrm{Xrs}$ is still uncertain, high $\Delta \mathrm{Xrs}$ values at low frequencies may derive from the presence of airway abnormalities, including expiratory flow limitations and decreases in lung volume in our cohort. It has been reported that small airway abnormalities are involved in RA patients even when the CT findings show IP dominant patterns or normal shadow (Mori et al. 2011; Faria et al. 2012) different from idiopathic IP and other collagen vascular diseases-related IP.

Impedance parameters, R4, R20, R36, and X4, significantly correlated with most parameters of the pulmonary function test (Table 3). X4 significantly correlated with parameters for restrictive abnormalities $(\mathrm{VC}, \% \mathrm{VC}$, FVC, \%FVC, TLC, and \%TLC), consistent with previous findings in IP (Fujii et al. 2015). These findings indicate that $\mathrm{X} 4$ values may be useful to detect lung volume and restrictive abnormalities. However, absolute Xrs and Rrs 

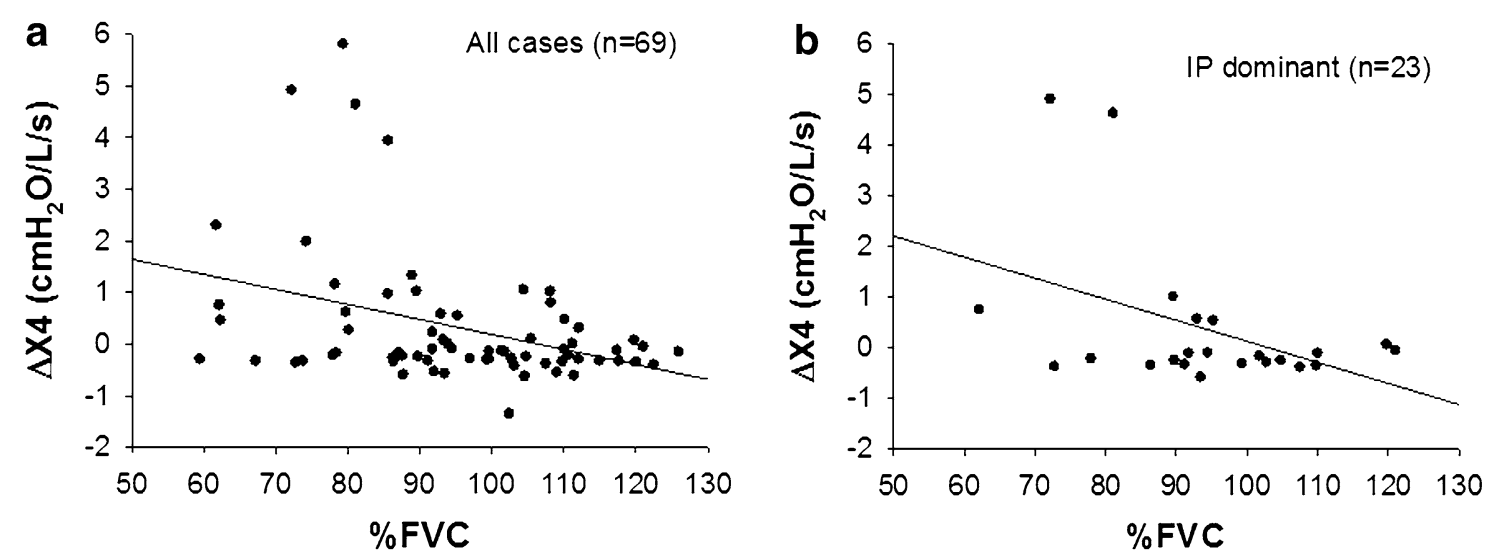

Fig. 5 Correlations between \% of the predicted value for forced vital capacity (\%FVC) and $\Delta X r s$ at $4 \mathrm{~Hz}(\Delta X 4)$ in all cases $(n=69$, a) and IP dominant group $(n=23, \mathbf{b})$

values should be evaluated carefully. It is well-known that Zrs values are affected by body size, specifically height, gender, and age, similar to those of the pulmonary function test (Oostveen et al. 2013). In our RA cohort, height significantly correlated with R4, R20, and R36 (Table 3). Although previous studies have tried to establish reference data from healthy subjects, standardized predictive values have not been established yet (Oostveen et al. 2003; Shiota et al. 2005; Oostveen et al. 2013). Moreover, the impedance data may vary between different FOT devices used for the measurements (Oostveen et al. 2013; Tanimura et al. 2014). Future studies are necessary to establish the methodology and reference values for Zrs measurements.

This study has several limitations. The data were retrospectively collected from RA patients with multiple respiratory disorders and different smoking statuses. Relatively high prevalence of obstructive abnormality $\left(\mathrm{FEV}_{1} /\right.$ $\mathrm{FVC}<0.70$ ) in the spirometry and emphysema in the CT findings suggests involvement of COPD. It is widely recognized that pulmonary manifestations in RA are heterogeneous (Tanaka et al. 2004). Although it is possible that a smoking history itself affects pulmonary functions and respiratory mechanics, pulmonary inflammation due to cigarette smoking is an important risk factor for developing RA specifically via anti-CCP antibody production (Klareskog et al. 2006). An association between positive anti-CCP antibody or RF and pulmonary complications of RA has been proposed (Klareskog et al. 2008; Reynisdottir et al. 2014). Consistent with those previous findings, the prevalence of anti-CCP antibody and RF was relatively high ( 88.2 and $86.3 \%$, respectively), most of which had abnormal findings on chest $\mathrm{CT}$ images. Therefore, effects of smoking cannot be ignored to understand clinical characteristics and pathophysiology of RA-related pulmonary diseases. Interestingly, there was no significant difference in the Zrs parameters (Rrs, Xrs and $\Delta \mathrm{Xrs}$ ) between ever and never smokers due to large variability (Additional file 2: Figure S2). Bronde et al. reported that the prevalence of COPD and asthma in RA patients was 25 and $18 \%$, respectively, significantly higher than those without RA in a population-based study in Ontario, Canada (Brode et al. 2014). Taken together, our cases involving heterogeneous pulmonary abnormalities, different smoking statuses, and obstructive abnormality are likely to reflect a real-world clinical setting of patients with RArelated pulmonary diseases. Another limitation of the present study is that the healthy control subjects were not matched to the RA group and younger than RA patients. The Zrs results of our healthy subjects such as frequencyindependent behavior in Rrs and within-breath behavior in Xrs (Fig. 2) are adequate as normal control data consistent with those in the previous reports (Kanda et al. 2010; Faria et al. 2012). However, prospective studies with a larger number of subjects including patients both with and without pulmonary abnormalities as well as healthy controls are necessary to characterize in more detail the respiratory impedance of RA.

\section{Conclusion}

The respiratory mechanics together with pulmonary functions and CT findings were characterized in patients with RA-related airway and parenchymal abnormalities. Significant frequency-dependence in the Rrs parameters was found in the RA patients but not in the healthy subjects. It is likely that respiratory physiology of RA-related IP is different from those of idiopathic IP. Because impedance measurements are not invasive, FOT may become a useful tool to evaluate alterations in respiratory functions in RA patients in the future. 


\section{Methods Subjects}

Patients who met the 1987 American College of Rheumatology classification criteria for RA and attended the outpatient clinic of the Department of Respiratory Medicine, Nagoya University Hospital, between July 2010 and November 2012 were retrospectively reviewed. Sixtynine patients on whom Zrs measurements, pulmonary function test, and CT examination had been performed were enrolled in this study. Healthy control data obtained from the hospital staff of our previous publication (Uchida et al. 2013) were re-analyzed for the impedance results (Additional file 3: Table S1).

\section{Pulmonary function tests}

After impedance measurements, spirometry was performed and lung volumes were determined using computerized equipment (Fudak77, Fukuda Sangyo, Tokyo, Japan). The following spirometric parameters, vital capacity, $\mathrm{FVC}, \mathrm{FEV}_{1}$, and $\mathrm{FEF}_{25-75}$, were measured. Lung volumes including residual volume and TLC were measured by means of the helium dilution technique. $\mathrm{DL}_{\mathrm{CO}}$ and its value corrected for alveolar volume $\left(\mathrm{DL}_{\mathrm{CO}} / \mathrm{V}_{\mathrm{A}}\right)$ were measured by the single-breath technique. Data were given as \% of the predicted values for spirometry and lung volumes calculated according to the method of the Japanese Respiratory Society (Japanese-Respiratory-Society 2004).

\section{Respiratory impedance measurements}

Impedance data was collected by FOT using a commercially available machine (MostGraph-01; Chest M.I., Tokyo, Japan) that generates a broad-band waveform at frequencies from 4 to $36 \mathrm{~Hz}$ in $4 \mathrm{~Hz}$ steps as described previously (Uchida et al. 2013). Briefly, impulse oscillatory signals generated by a loud speaker at intervals of $0.25 \mathrm{~s}$ were applied to the respiratory system during tidal breathing at rest. The Zrs was calculated using the system computer algorithms. The Zrs was recorded for approximately $20 \mathrm{~s}$ (5-6 respiratory cycles) while the patients firmly supported their cheeks with their palms in the sitting position using a nose clip with the neck in a comfortable neutral posture. Upper airway artifacts resulting from glottal changes, air leaks, and cheek support techniques during measurements significantly affect the impedance results (Peslin et al. 1985; Uchida et al. 2013; Bikov et al. 2015). Therefore, such upper airway artifacts were carefully eliminated. Three to five technically acceptable measurements were performed as recommended in the guidelines (Oostveen et al. 2003).

\section{Analysis of impedance results}

The actual values of Rrs and Xrs at given frequencies between 4 and $36 \mathrm{~Hz}$ were analyzed in this study. Each impedance parameter was expressed as a mean value during a respiratory cycle, whole-breath, inspiration, and expiration. $\Delta$ Xrs were calculated as mean inspiratory values minus mean expiratory values according to a method by Dellaca et al. (2004).

\section{Interpretation of CT examinations}

CT data were obtained using a 64-row or 16-row multidetector row CT (Aquilion64 or Aquilion16; Toshiba Medical Systems Corp., Tokyo, Japan). Patients were scanned in the craniocaudal direction with inspiratory apnea. The slice thickness and reconstruction interval of HRCT were $0.5-/ 1.0-\mathrm{mm}$ and $0.5-/ 1.0-\mathrm{mm}$, respectively, using a high-spatial frequency algorithm. Routine CT (5-mm slice thickness and 5-mm interval) were also reconstructed. Both HRCT and routine CT were available for 66 cases $(95.7 \%)$, while only routine CT was available for 3 (4.3\%) cases. The radiological diagnosis was made by an experienced thoracic radiologist (S. Iw) and defined based on a previous report by Tanaka et al. (2004). The extent of CT findings was graded subjectively with a five-point scale within the whole lung field as follows: grade 0 , the finding was absent; grade 1 , the percentage of involvement of the lungs was between 1 and $25 \%$; grade 2 , the percentage of involvement was between 26 and $50 \%$; grade 3 , the percentage of involvement was between 51 and $75 \%$; and grade 4, the percentage of involvement was more than $76 \%$ (Tanaka et al. 2004). He was blinded to the patients' clinical information except that all patients had RA. Then, the diagnosis was reviewed by chest physicians (R.S and H.A.). Each $\mathrm{CT}$ finding was categorized as one of four types: airway lesion dominant, IP dominant, mixed (both airway lesion and IP) pattern, and others (Mori et al. 2012).

\section{Statistical analysis}

Repeated-measure ANOVA followed by Bonferroni's post hoc test or $t$ test was used to evaluate the statistical significance (SigmaPlot11.0; Systat Software Inc., San Jose, CA). When data failed a normality test, ANOVA on ranks followed by a Tukey test or Mann-Whitney test was used. $P<0.05$ was considered statistically significant. Correlations between valuables were analyzed using the Spearman's rank or Pearson's correlation coefficient. Fisher's exact test was used to evaluate significance in group differences in various categories. Data were given as mean $\pm \mathrm{SD}$. 
Ethics, consent and permissions and consent to publish This retrospective study was approved by the local ethics committee of Nagoya University Hospital (approval No. 2012-0352, 2015-0061). No patient identifiers were included. The informed consent requirement to participate and publish was waived for this retrospective analysis. The study information was disclosed to the target patients via the internet $\mathrm{s}$ at Nagoya University Hospital to allow the candidate patients to refuse to participate.

\section{Additional files}

Additional file 1: Figure S1. Representative CT images of airway lesion dominant and IP dominant patterns.

Additional file 1: Figure S2. Respiratory impedance of smokers and never smokers.

Additional file 3: Table S1. Clinical characteristics of healthy control subjects.

\section{Abbreviations}

ANOVA: analysis of variance; anti-CCP: anti-cyclic citrullinated peptide; COPD: chronic obstructive pulmonary disease; $C T$ : computed tomography; $\Delta$ : the difference between inspiratory and expiratory phases; $\mathrm{DL}_{\mathrm{co}}$ : diffusing capacity of the lung for carbon monoxide; $\mathrm{FEF}_{25-75}$ : forced expiratory flow from 25 to $75 \%$ of forced vital capacity; FEV 1 : forced expiratory volume in $1 \mathrm{~s}$; FOT: forced oscillation technique; FRC: functional residual capacity; FVC: forced vital capacity; Rrs: respiratory resistance; R4: Rrs at $4 \mathrm{~Hz}$; R20: Rrs at $20 \mathrm{~Hz}$; R36: Rrs at 36 $\mathrm{Hz}$; RA: rheumatoid arthritis; RF: rheumatoid factor; TLC: total lung capacity; $V_{A}$ : alveolar volume; $\mathrm{VC}$ : vital capacity; Xrs: respiratory reactance; X4: Xrs at $4 \mathrm{~Hz}$; Zrs: respiratory impedance.

\section{Authors' contributions}

$\mathrm{AU}, \mathrm{HA}$, and MK undertook the measurements and analyses of data; RS, SIt, SIw, and TK analyzed the data and wrote the manuscript; $\mathrm{NI}$ and $\mathrm{YH}$ supervised the research work. All the authors read and approved the final manuscript.

\section{Author details}

'Department of Respiratory Medicine, Nagoya University School of Medicine, Nagoya 466-8550, Japan. ${ }^{2}$ Department of Radiology, Nagoya University School of Medicine, Nagoya 466-8550, Japan. ${ }^{3}$ Department of Clinical Laboratory, Nagoya University School of Medicine, Nagoya 466-8550, Japan. ${ }^{4}$ Department of Orthopedic Surgery and Rheumatology, Nagoya University School of Medicine, Nagoya 466-8550, Japan.

\section{Acknowledgements}

The authors thank Ms. Katherine Ono for providing language help. We also thank Ms. Marika Endo (CHEST M.I.) for technical advice.

\section{Competing interests}

The authors declare they have no competing interests.

Received: 27 August 2015 Accepted: 29 February 2016

Published online: 15 March 2016

\section{References}

Bates JH, Irvin CG, Farre R, Hantos Z (2011) Oscillation mechanics of the respiratory system. Compr Physiol 1:1233-1272

Biederer J, Schnabel A, Muhle C, Gross WL, Heller M, Reuter M (2004) Correlation between HRCT findings, pulmonary function tests and bronchoalveolar lavage cytology in interstitial lung disease associated with rheumatoid arthritis. Eur Radiol 14:272-280
Bikov A, Pride NB, Goldman MD, Hull JH, Horvath I, Barnes PJ, Usmani OS, Paredi P (2015) Glottal aperture and buccal airflow leaks critically affect forced oscillometry measurements. Chest 148:731-738

Brode SK, Jamieson FB, Ng R, Campitelli MA, Kwong JC, Paterson JM, Li P, Marchand-Austin A, Bombardier C, Marras TK (2014) Risk of mycobacterial infections associated with rheumatoid arthritis in Ontario, Canada. Chest 146:563-572

Brown KK (2007) Rheumatoid lung disease. Proc Am Thorac Soc 4:443-448 Cauberghs M, Van De Woestijne KP (1992) Changes of respiratory input impedance during breathing in humans. J Appl Physiol 73:2355-2362

Cortet B, Perez T, Roux N, Flipo RM, Duquesnoy B, Delcambre B, Remy-Jardin M (1997) Pulmonary function tests and high resolution computed tomography of the lungs in patients with rheumatoid arthritis. Ann Rheum Dis 56:596-600

Dellaca RL, Santus P, Aliverti A, Stevenson N, Centanni S, Macklem PT, Pedotti A, Calverley PM (2004) Detection of expiratory flow limitation in COPD using the forced oscillation technique. Eur Respir J 23:232-240

Di Mango AM, Lopes AJ, Jansen JM, Melo PL (2006) Changes in respiratory mechanics with increasing degrees of airway obstruction in COPD: detection by forced oscillation technique. Respir Med 100:399-410

Dubois AB, Brody AW, Lewis DH, Burgess BF Jr (1956) Oscillation mechanics of lungs and chest in man. J Appl Physiol 8:587-594

Faria AC, Barbosa WR, Lopes AJ, Pinheiro Gda R, Melo PL (2012) Contrasting diagnosis performance of forced oscillation and spirometry in patients with rheumatoid arthritis and respiratory symptoms. Clinics 67:987-994

Fujii M, Shirai T, Mori K, Mikamo M, Shishido Y, Akita T, Morita S, Asada K, Suda T (2015) Inspiratory resonant frequency of forced oscillation technique as a predictor of the composite physiologic index in interstitial lung disease. Respir Physiol Neurobiol 207:22-27

Fuld JP, Johnson MK, Cotton MM, Carter R, Watkin SW, Capell HA, Stevenson RD (2003) A longitudinal study of lung function in nonsmoking patients with rheumatoid arthritis. Chest 124:1224-1231

Grimby G, Takishima T, Graham W, Macklem P, Mead J (1968) Frequency dependence of flow resistance in patients with obstructive lung disease. J Clin Invest 47:1455-1465

Hantos Z, Daroczy B, Suki B, Nagy S, Fredberg JJ (1992) Input impedance and peripheral inhomogeneity of dog lungs. J Appl Physiol 72:168-178

Hasegawa K, Sato S, Tanimura K, Fuseya Y, Uemasu K, Sato A, Hirai T, Mishima M, Muro S (2015) Emphysema and airway disease affect within-breath changes in respiratory resistance in COPD patients. Respirology 20:775-781

Ito S, Lutchen KR, Suki B (2007) Effects of heterogeneities on the partitioning of airway and tissue properties in normal mice. J Appl Physiol 102:859-869

Ito S, Ko SB, Morioka M, Imaizumi K, Kondo M, Mizuno N, Hasegawa Y (2012) Three cases of bronchial asthma preceding lgG4-related autoimmune pancreatitis. Allergol Int 61:171-174

Japanese-Respiratory-Society (2004) Guidelines of respiratory function testsspirometry, flow-volume curve, diffusion capacity of the lung. Nihon Kokyuki Gakkai Zasshi 42:1-56

Kanda S, Fujimoto K, Komatsu Y, Yasuo M, Hanaoka M, Kubo K (2010) Evaluation of respiratory impedance in asthma and COPD by an impulse oscillation system. Intern Med 49:23-30

Kinoshita F, Hamano H, Harada H, Kinoshita T, Igishi T, Hagino H, Ogawa T (2004) Role of KL-6 in evaluating the disease severity of rheumatoid lung disease: comparison with HRCT. Respir Med 98:1131-1137

Klareskog L, Stolt P, Lundberg K, Kall berg H, Bengtsson C, Grunewald J, Ronnelid J, Harris HE, Ulfgren AK, Rantapaa-Dahlqvist S, Eklund A, Padyukov L, Alfredsson L (2006) A new model for an etiology of rheumatoid arthritis: smoking may trigger HLA-DR (shared epitope)-restricted immune reactions to autoantigens modified by citrullination. Arthritis Rheum 54:38-46

Klareskog L, Ronnelid J, Lundberg K, Padyukov L, Alfredsson L (2008) Immunity to citrullinated proteins in rheumatoid arthritis. Annu Rev Immunol 26:651-675

Lutchen KR, Greenstein JL, Suki B (1996) How inhomogeneities and airway walls affect frequency dependence and separation of airway and tissue properties. J Appl Physiol 80:1696-1707

Michaelson ED, Grassman ED, Peters WR (1975) Pulmonary mechanics by spectral analysis of forced random noise. J Clin Invest 56:1210-1230 
Miranda IA, Dias Faria AC, Lopes AJ, Jansen JM, Lopes De Melo P (2013) On the respiratory mechanics measured by forced oscillation technique in patients with systemic sclerosis. PLoS ONE 8:e61657

Mori S, Cho I, Koga Y, Sugimoto M (2008) Comparison of pulmonary abnormalities on high-resolution computed tomography in patients with early versus longstanding rheumatoid arthritis. J Rheumatol 35:1513-1521

Mori S, Koga Y, Sugimoto M (2011) Small airway obstruction in patients with rheumatoid arthritis. Mod Rheumatol 21:164-173

Mori S, Koga Y, Sugimoto M (2012) Different risk factors between interstitial lung disease and airway disease in rheumatoid arthritis. Respir Med 106:1591-1599

Mori K, Shirai T, Mikamo M, Shishido Y, Akita T, Morita S, Asada K, Fujii M, Hozumi H, Suda T, Chida K (2013) Respiratory mechanics measured by forced oscillation technique in combined pulmonary fibrosis and emphysema. Respir Physiol Neurobiol 185:235-240

Ohishi J, Kurosawa H, Ogawa H, Irokawa T, Hida W, Kohzuki M (2011) Application of impulse oscillometry for within-breath analysis in patients with chronic obstructive pulmonary disease: pilot study. BMJ Open 1:e000184

Olson AL, Swigris JJ, Sprunger DB, Fischer A, Fernandez-Perez ER, Solomon J, Murphy J, Cohen M, Raghu G, Brown KK (2011) Rheumatoid arthritisinterstitial lung disease-associated mortality. Am J Respir Crit Care Med 183:372-378

Oostveen E, Macleod D, Lorino H, Farre R, Hantos Z, Desager K, Marchal F (2003) The forced oscillation technique in clinical practice: methodology, recommendations and future developments. Eur Respir J 22:1026-1041

Oostveen E, Boda K, Van Der Grinten CP, James AL, Young S, Nieland H, Hantos Z (2013) Respiratory impedance in healthy subjects: baseline values and bronchodilator response. Eur Respir J 42:1513-1523

Paredi P, Goldman M, Alamen A, Ausin P, Usmani OS, Pride NB, Barnes PJ (2010) Comparison of inspiratory and expiratory resistance and reactance in patients with asthma and chronic obstructive pulmonary disease. Thorax 65:263-267

Perez T, Remy-Jardin M, Cortet B (1998) Airways involvement in rheumatoid arthritis: clinical, functional, and HRCT findings. Am J Respir Crit Care Med 157:1658-1665

Peslin R, Duvivier C, Gallina C, Cervantes P (1985) Upper airway artifact in respiratory impedance measurements. Am Rev Respir Dis 132:712-714

Peslin R, Ying Y, Gallina C, Duvivier C (1992) Within-breath variations of forced oscillation resistance in healthy subjects. Eur Respir J 5:86-92
Pride NB (1992) Forced oscillation techniques for measuring mechanical properties of the respiratory system. Thorax 47:317-320

Reynisdottir G, Karimi R, Joshua V, Olsen H, Hensvold AH, Harju A, Engstrom M, Grunewald J, Nyren S, Eklund A, Klareskog L, Skold CM, Catrina Al (2014) Structural changes and antibody enrichment in the lungs are early features of anti-citrullinated protein antibody-positive rheumatoid arthritis. Arthritis Rheumatol 66:31-39

Shiota S, Katoh M, Fujii M, Aoki S, Matsuoka R, Fukuchi Y (2005) Predictive equations and the reliability of the impulse oscillatory system in Japanese adult subjects. Respirology 10:310-315

Shirai T, Mori K, Mikamo M, Shishido Y, Akita T, Morita S, Asada K, Fujii M, Suda T, Chida K (2013) Respiratory mechanics and peripheral airway inflammation and dysfunction in asthma. Clin Exp Allergy 43:521-526

Sugiyama A, Hattori N, Haruta Y, Nakamura I, Nakagawa M, Miyamoto S, Onari Y, Iwamoto H, Ishikawa N, Fujitaka K, Murai H, Kohno N (2013) Characteristics of inspiratory and expiratory reactance in interstitial lung disease. Respir Med 107:875-882

Tanaka N, Kim JS, Newell JD, Brown KK, Cool CD, Meehan R, Emoto T, Matsumoto T, Lynch DA (2004) Rheumatoid arthritis-related lung diseases: CT findings. Radiology 232:81-91

Tanimura K, Hirai T, Sato S, Hasegawa K, Muro S, Kurosawa H, Mishima M (2014) Comparison of two devices for respiratory impedance measurement using a forced oscillation technique: basic study using phantom models. J Physiol Sci 64:377-382

Tsuchiya Y, Takayanagi N, Sugiura H, Miyahara Y, Tokunaga D, Kawabata Y, Sugita Y (2011) Lung diseases directly associated with rheumatoid arthritis and their relationship to outcome. Eur Respir J 37:1411-1417

Turesson C, O'fallon WM, Crowson CS, Gabriel SE, Matteson EL (2003) Extraarticular disease manifestations in rheumatoid arthritis: incidence trends and risk factors over 46 years. Ann Rheum Dis 62:722-727

Uchida A, Ito S, Suki B, Matsubara H, Hasegawa Y (2013) Influence of cheek support on respiratory impedance measured by forced oscillation technique. SpringerPlus 2:342

Van Noord JA, Clement J, Cauberghs M, Mertens I, Van De Woestijne KP, Demedts M (1989) Total respiratory resistance and reactance in patients with diffuse interstitial lung disease. Eur Respir J 2:846-852

\section{Submit your manuscript to a SpringerOpen ${ }^{\circ}$ journal and benefit from:}

- Convenient online submission

- Rigorous peer review

- Immediate publication on acceptance

- Open access: articles freely available online

- High visibility within the field

- Retaining the copyright to your article

Submit your next manuscript at springeropen.com 